\title{
A NEW SILPHID BEETLE FROM A SIMPLE INSECT-TRAP.*
}

BY A. LEONARD MELANDER, AUSTIN, TEX.

The curiosity of an investigating ant may sometimes lead it to destruction. During the month of November last, having had occasion to use a large quantity of the common Texas "stinging red ant" (Pogonomyrmex barbatus var. molefaciens Buckley) we selected as the easiest and quickest method of capture a novel expedient. A number of four-ounce bottles were sunk in the gravel nest-heap close to the entrance, nearly to the level of the ground, and then were left opened. The ants ready to resent this disturbance immediately hurried up the little embankment to the open bottles and in their precipitous rush fell headlong over the edge, after which they were unable to crawl up the smooth surface of the glass. After the first excitement the ants largely neglected the traps but now and then a passer-by would peer over the edge, doubtless called there by the stridulation of the ants within, and losing its insecure foothold would topple over into the bottle.

In the course of our regular visits to these automatic traps we noticed that in the early morning each bottle invariably contained one or more specimens of a small fly that quickly effected its escape at the slightest noise. After several vain attempts the flies were at last secured by simply corking the bottle, and upon

* Contributions from the Zoological Laboratory of the University of Texas No. 28. examination proved to be a form belonging to the cave-dwelling genus Leria (Blepharoptera), L. pectinata, originally described by Dr. Loew from this state.

The propensity of this species to seek a bottle as a substitute for a burrow opens a new and interesting field for collecting myrmecophilous and cavernfrequenting insects. That this fly is probably a true myrmecophile, habitually using the burrows of the agricultural ant as its domicile, is quite possible, and even probable when we consider that only the bottles sunk in the ant-nests yielded specimens, though numerous bottles had been arranged as control experiments in the open fields close by, and moreover even if placed on the antbed the bottles never contained a fly when there were no ants within.

Aside from the Leria and the everpresent Eleodes tricostata, which in its capacity of scavenger is always found scurrying over the ant-beds, another insect was taken in great numbers. This one, an exceedingly active little Silphid beetle, is closely related to Ptomophagus parasitus Leconte, another ant-guest, which has been taken in the Eastern States in nests of Formica. The present beetle belongs to the division Catopomorphus of the genus, but distinctly differs from its relative in the approximation of the elytral strigae, and in its selection of a host of another sub- 
family - a biological difference that must not be underrated.*

Although a number of the flies and beetles were confined in the bottles with the ants for several days they rested unharmed, evidently the closest intimacy existing between the three. The beetles would run about among the ants or fly in the bottle with a quick darting movement, but at no time were the ants observed to molest either of their guests. This is interesting especially in the case of the Leria which has never before been found associating with ants, and which, were the ants unfriendly toward it, might be supposed to have accidently used the ant-burrow in place of some other suitable excavation.

Ptomophagus texanus sp. nov.

Length 2.75-3. mm. Form elongate oval, Mordellid-like, slightly narrowed posteriorly ; color dark castaneous, shining, thorax almost piceous. Head, thorax, and elytra uniformly, closely and finely strigose, the strigae provided with short closely-placed, uniform,

*In a list of the myrmecophilous Coleoptera of Northern America Mr. E. A. Schwarz in 1890 notices the occurrence of another Ptomophagus in ant-nests but as far as I am aware this species has not yet been described. Leria pectinata has previously been found by Mr. H. G. Hubbard associating with Ptomophagus fisus Horn in the upper burrows of desert rodents in Arizona. (Proc. Ent. Soc. Wash. IV., p. 362). In this connection may be cited the finding of Ptomophagus in a cave (Pt. cavernicola Schwarz), a habit further bearing on the preceding observation. golden yellow pubescence; that of the head radiating from the vertex, that of the thorax and elytra directed straight backwards. An. ten nae not reaching the hind angles of the thorax, the first four joints fuscous, moderately slender, the first and second joints long, joints six to eleven broader and shorter, piceous, the eighth joint two-thirds as long as the ninth, and not appreciably narrower. Thorax fully two-thirds as long as the width of its base, the sides gradually then quickly narrowing in front, hind angles acute, base feebly but distinctly bisinuate, the narrow hind margin more or less castaneous; disc of the thorax strigose as well as the sides, the strigae conforming more or less with the front margin. The strigae of the elytra not transverse but more or less conforming with the posterior margin : sutural stria well impressed nearly to the apex; sutural angles rounded in the male, but provided with a distinct angle in the female. Body beneath finely and sparsely punctate and pubescent, the femora wholly strigose similarly to the upper surface of the body : tibial spurs equal, those of the hind legs one-third the length of the metatarsus.

Described from ten males, and thirteen females, taken, as above mentioned, at Austin, Texas. The front tarsi of the male are flattened and broadened. The tips of the tibiae are fimbriate apically with short equal spines, which, as the strigosity of the thorax is distinct, further confirm Dr. Horn's statement that these characters are correlated in this genus. 

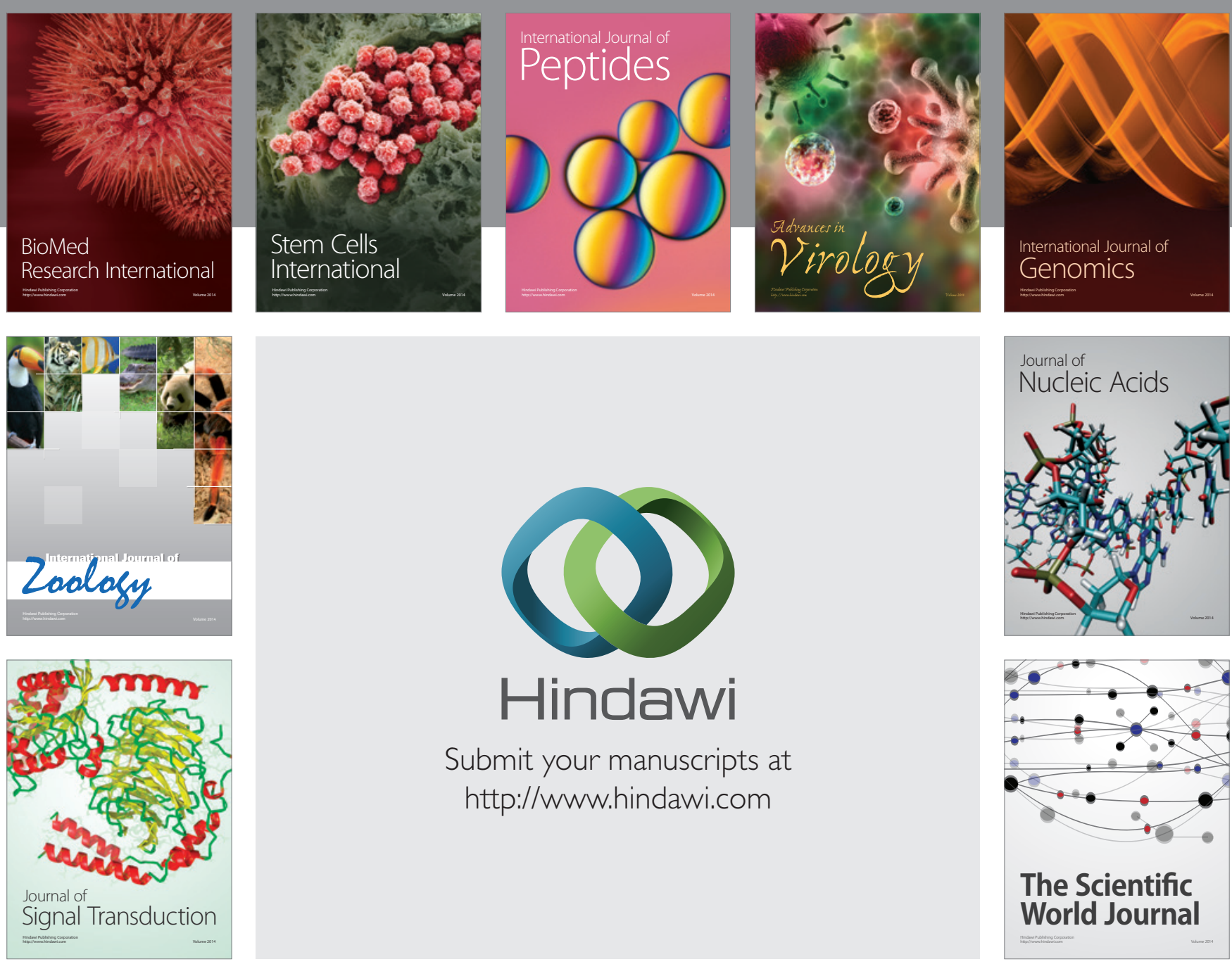

Submit your manuscripts at

http://www.hindawi.com
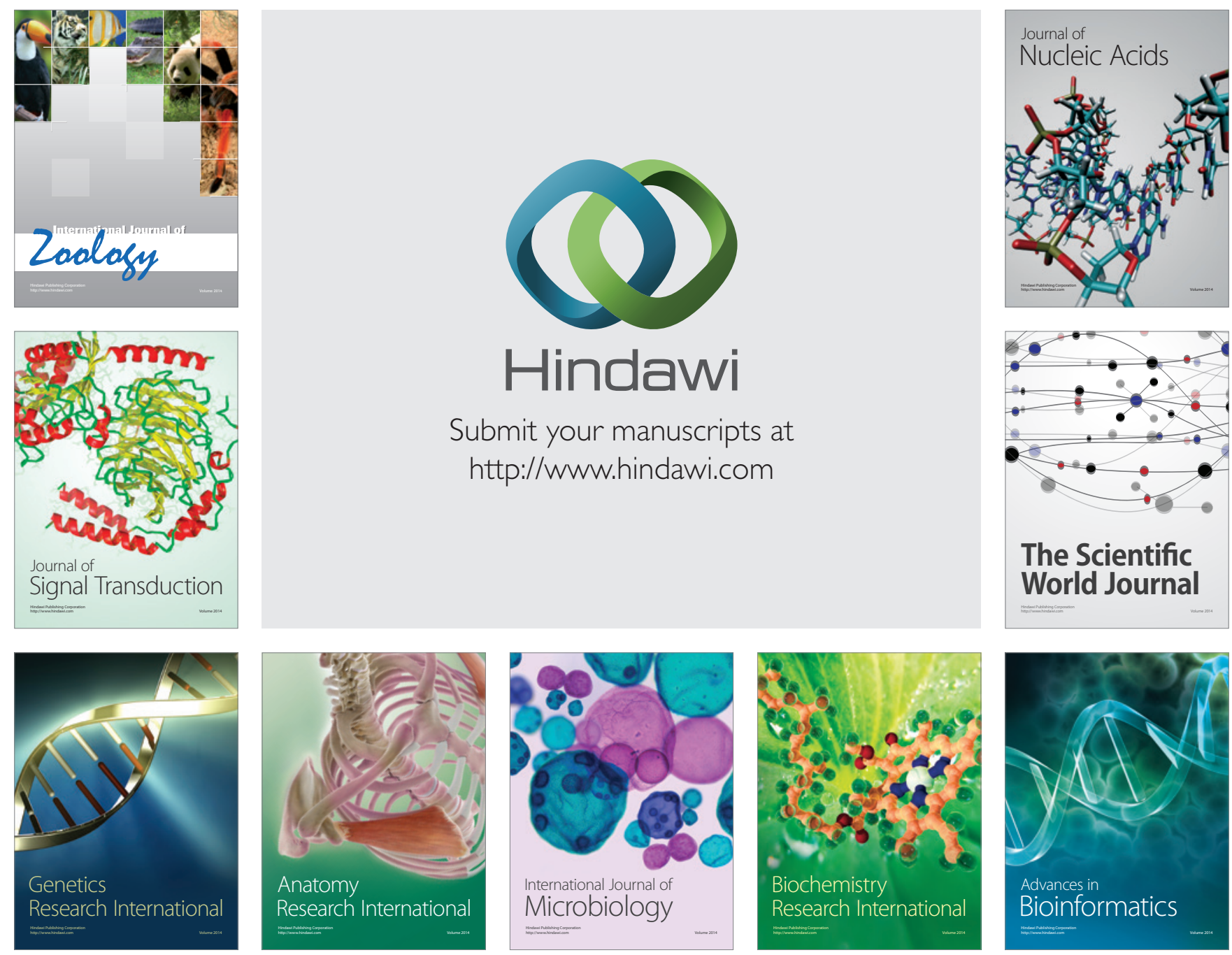

The Scientific World Journal
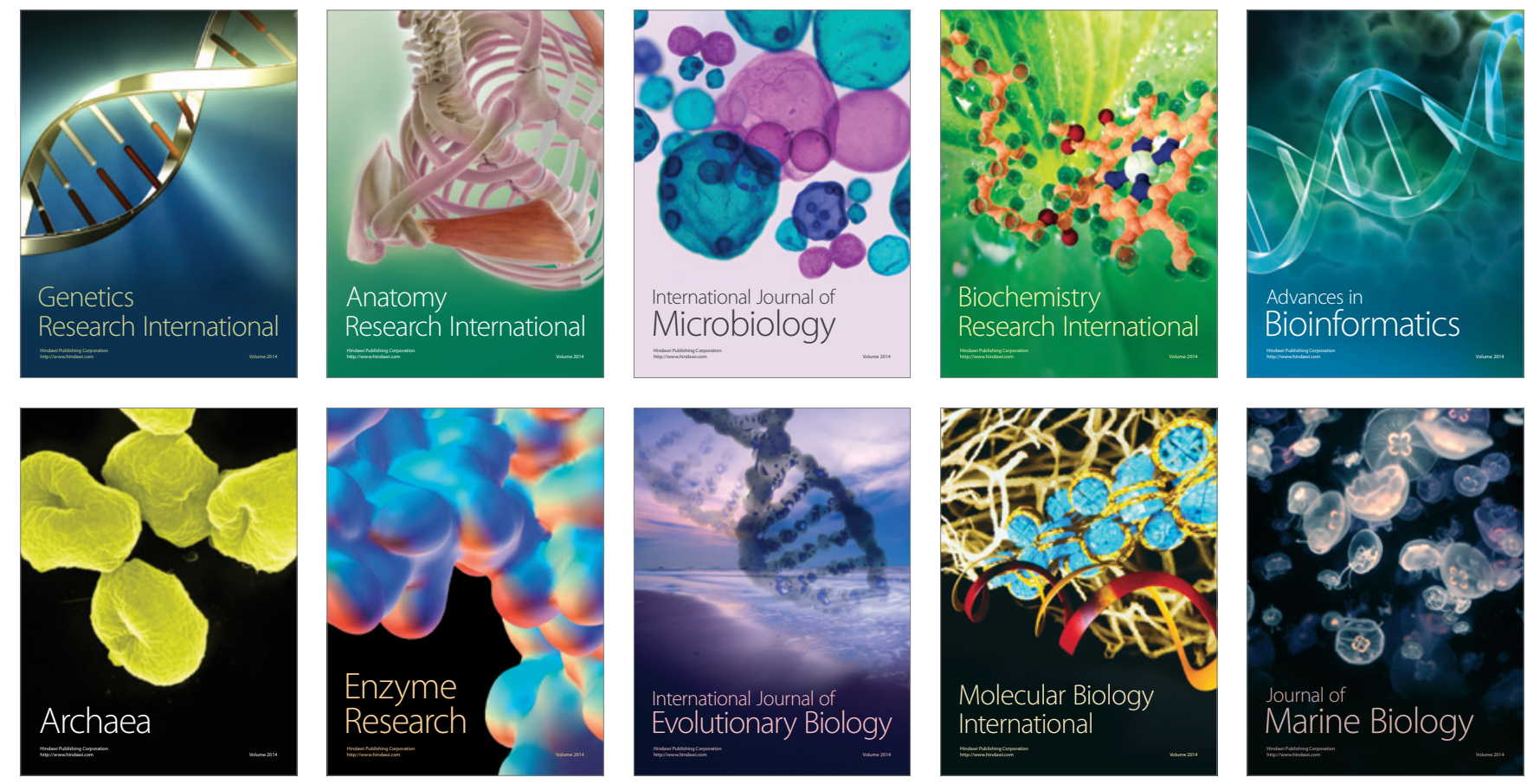